(6) OPEN ACCESS

${ }^{1}$ Department of Training \& Exercise Science, Faculty of Sport Science, Bochum, Germany

${ }^{2}$ Sports Research Centre, Miguel Hernandez University, Elche, Spain

\section{Correspondence to} Dr Jaime Fernandez-Fernandez, Training Analysis and Optimization, Sports Research Centre, Miguel Hernandez University, Avda Universidad s/n, Elche, Alicante 03202, Spain;

jaime.fernandez@umh.es

Accepted 17 January 2014

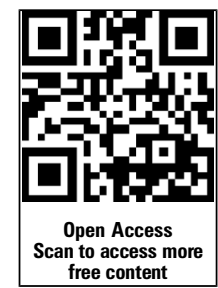
2014;48:i22-i31.

\title{
Fitness testing of tennis players: How valuable is it?
}

\author{
Jaime Fernandez-Fernandez, ${ }^{1,2}$ Alexander Ulbricht, ${ }^{1}$ Alexander Ferrauti ${ }^{1}$
}

\begin{abstract}
In tennis, sport-specific technical skills are predominant factors, although a complex profile of physical performance factors is also required. The fitness test batteries assist in examining tennis players' capabilities for performance at different levels in the laboratory as well as in the field, in the junior or elite level. While laboratory tests can be, and are, used to evaluate basic performance characteristics of athletes in most individual sports, in a more specific approach, field-based methods are better suited to the demands of complex intermittent sports like tennis. A regular test battery performed at different periods of the year allows to obtain an individual's performance profile, as well as the ability to prescribe individual training interventions. Thus, the aim of the present review was to describe and evaluate the different physical tests recommended and used by practitioners, sports scientists and institutions (national tennis federations).
\end{abstract}

\section{INTRODUCTION}

Tennis has evolved from a sport in which skill was the primary prerequisite for successful performance into a sport that also requires complex interaction of several physical components (ie, strength and agility) and metabolic pathways (ie, aerobic and anaerobic). ${ }^{1}$ To target these traits and maximise individual improvements, as well as training efficiency, goals and content must be defined according to (1) a specific workload and the most important limiting performance factors and (2) individual technical and physical needs, in order to achieve an optimum cost-benefit ratio of training input. In this context, it is important to have enough basic and representative research to provide general guidelines, so that players and coaches obtain objective information about the players' physical performance. Thus, a general and individual adjustment of short-term and long-term training programmes is ensured, providing objective feedback and motivating coaches and players to work better. $^{2}$

In the long-term athlete development structure, a basic precondition is the regular assessment of physical performance, ${ }^{3}{ }^{4}$ which is also an integral part of sports science support for athletes. We can distinguish between single testing procedures and complex test batteries, and all measurements have to consider the specific criteria of proper testing, which are validity, reliability and objectivity. ${ }^{3}$ Laboratory or field-based tests can be distinguished and seem to be fundamental elements in profiling athletes, and quantifying training adaptation and programme efficacy. ${ }^{3} 56$ While laboratory tests are used to evaluate basic performance characteristics in most individual sports, field-based methods are better suited to the demands of complex intermittent sports like tennis, since the variability in energy system, muscle group and skill incorporated in their performance is difficult to replicate in the laboratory. ${ }^{7}$ Field tests seem to be more ecologically valid, allowing the testing of large numbers of participants simultaneously, they are generally easier to administer and can be used by practitioners as well as researchers. ${ }^{29}$ However, the testing surroundings in the laboratory show a higher standardisation and, therefore, coaches and scientists have to decide between a comparably higher validity and a lower but acceptable reliability (eg, specific field tests), compared with a lower validity and a correspondingly higher reliability (eg, laboratory tests). ${ }^{8}$

The development and application of physical tests in tennis should be integrated into a complex scientific approach, which can be used to construct a long-term sport-specific and individual training optimisation model (figure 1). A major first step in this model is the knowledge of the workload profile during competition, which could be defined as the description of the athletes' movement patterns combined with physiological demands (ie, heart rate (HR), sources of muscular energy). Thus, data obtained during tennis competition can be used as external criteria for the validation of tennisspecific tests and for the design of specific training interventions. ${ }^{1} 10-13$

Once a physical test or a test battery is standardised with representative data samples (eg, different levels of performance, age and sex groups), a statistical multiple regression approach should be applied using the national or international ranking position as external criteria to identify the most sensitive physical characteristics of performance. $^{14} 15$ This systematic approach is directly related to the specificity training principle, which states that to target these performance characteristics or components, and elicit specific adaptations, training must be focussed on the desired elements of performance. ${ }^{3}$

At the final stage of the schematic representation of the sport-specific training optimisation model (figure 1), tennis players have to regularly complete a test battery, which allows an individual performance profiling, and an individual prescription of training. This process has to be repeated in a regular feedback loop, while adapting training interventions to obtain changes in physical performance.

In tennis, research has been conducted with athletes of various backgrounds (eg, age, sex, performance level, etc) using different testing protocols with the aim of identifying the most influential factors on performance (ie, ranking). ${ }^{14}$ 16-19 However, there is general disagreement among the scientific community regarding the most important 
Figure 1 Schematic representation of the sport-specific training optimisation model.

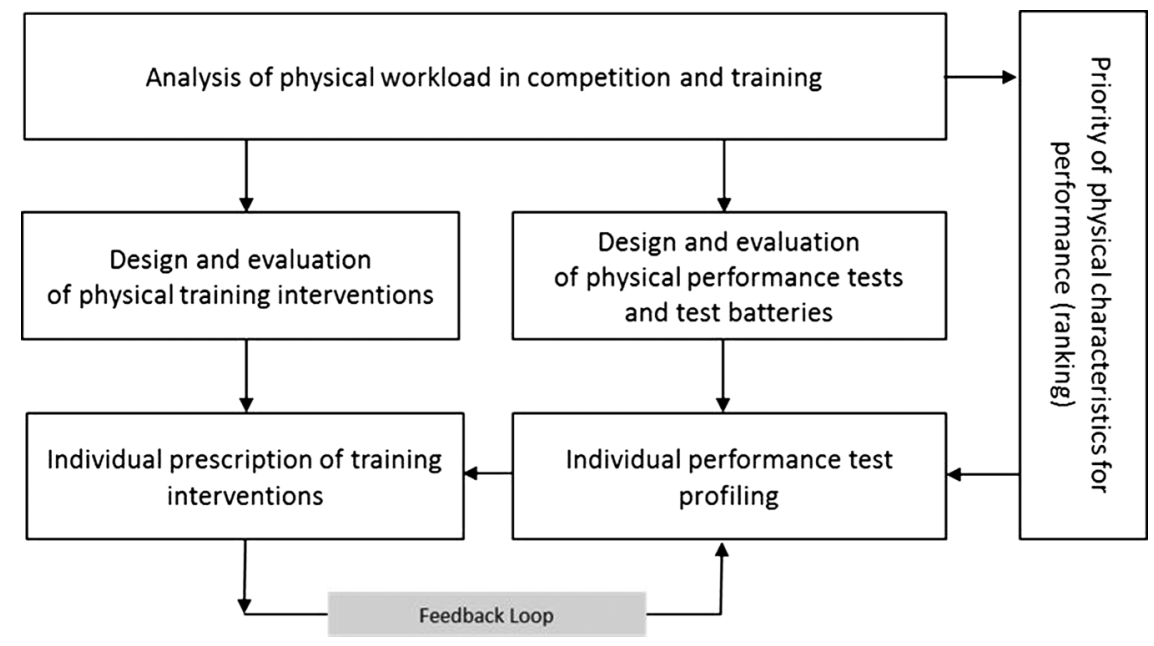

physical performance characteristics and useful tests in this sport. In the past few years, several protocols have been documented, mainly by national tennis federations, ${ }^{19-21}$ trying to cover the complex profile of physical qualities, however, with the assessment of technical skills usually excluded. Thus, the aim of the present review is to describe and evaluate the different physical tests recommended and used by practitioners, sport scientists and institutions (national tennis federations). As selection criteria for the testing procedures, only tennis-specific field tests were initially selected, followed by intermittent sportsrelated tests, while laboratory tests are not described in detail. Since some of the different physical qualities allow a less specific approach for physical testing (eg, strength and power), some basic tests are also included. The search included articles published prior to 1 September 2013, as well as theses/dissertations completed and available by the same date, using the PubMed search engine (http://www.pubmed.gov). The search was conducted using the terms 'tennis' combined with 'test' as well and 'endurance, strength, power, speed, agility and range of motion (ROM)'. Reference lists from retrieved studies as well as official publications of the International Tennis Federation (ITF) and national tennis federations were also reviewed.

\section{Physical demands during tennis play}

Tennis match play is characterised by intermittent whole body efforts, alternating short (2-10 s) bouts of high-intensity exercise and short (10-20s) recovery bouts interrupted by several resting periods of longer duration (60-90 s), with a typical average match time of $1.5 \mathrm{~h}$, although in some cases it can last for more than 5 h. ${ }^{1} 1222$ After serving around $200 \mathrm{~km} / \mathrm{h}$, a tennis player runs an average of $3 \mathrm{~m}$ per shot and a total of 8-15 $\mathrm{m}$ with 3-4 changes of direction in the pursuit of one point, hitting the ball an average of 4-5 times and completing 1300 to $3600 \mathrm{~m}$ per hour of play, depending on the player's level (amateur or advanced) and court surface (slow or fast). ${ }^{1} 22$ Typically, players must react quickly and be exceptional movers not only in a linear direction, but also multidirectionally. Strength is required in muscles and joints for performance (ball velocity) and to reduce injuries (protection of joints), while an adequate ROM in the main joints (ie, rotator cuff muscles) seems to be essential for strokes and on-court movement. ${ }^{22} 23$ From a physiological perspective, during long and fast rallies, tennis elicits average $\mathrm{HR}$ of $70-80 \%$ of maximum $\left(\mathrm{HR}_{\max }\right)$, and peak values around $100 \%$ of $\mathrm{HR}_{\max }$. Average oxygen uptake values correspond to approximately $50-60 \%$ of maximum oxygen consumption $\left(\mathrm{VO}_{2 \max }\right)$, with values above $80 \%$ of $\mathrm{VO}_{2 \max }$ during intensive rallies. ${ }^{1}{ }^{24}$ Thus, during match-play, demands alternate between energy provision for bouts of highintensity work (via intramuscular phosphates and glycolysis) and replenishing energy sources and restoring homeostasis during the intervals in between (by oxidative metabolism). ${ }^{25}$ Therefore, to be successful in competition and to tolerate intensive training demands, ${ }^{1}$ tennis players need a mixture of speed, agility and power combined with medium-to-high aerobic and anaerobic capabilities, related to whole body muscle groups.

\section{Aerobic endurance testing}

As previously mentioned, valid approaches for endurance testing in tennis should include a physical workload profile analysed during competition. However, this complex approach may as well as in the interpretation of results (eg, distinction between the different qualities of the underlying metabolic pathways). Thus, a look into the tennis literature concerning endurance testing provides an extreme variability of procedures, ranging from non-specific laboratory to more or less specific (semispecific) and tennis-specific field tests. ${ }^{26}$

\section{Laboratory tests}

Incremental exercise tests in the laboratory are generally accepted as a measure of aerobic power, and although they can be conducted on a variety of ergometers, a motorised treadmill is recommended for testing tennis players. ${ }^{26} \mathrm{~A}$ wide range of test protocols with different characteristics (ie, incremental stage durations and intensities, rest intervals and number of stages) are described elsewhere. ${ }^{27}$ The determination of $\mathrm{VO}_{2 \max }$ and blood lactate (La)-related thresholds are commonly used as general aerobic fitness markers of athletes, ${ }^{7} 28$ although sport scientists should maintain the testing protocol constant to guarantee an objective longitudinal comparison.

\section{Field-based tests} mill test protocols can be transferred to field conditions, ${ }^{29}$ allowing groups of players (eg, all players of a national or regional squad) to run simultaneously (eg, on a $400 \mathrm{~m}$ track divided into sections) and follow an acoustic signal. For practical reasons (eg, club level; no technical or physiological measurements available), the Cooper 12 min Run Test could be useful, ${ }^{30}$ although tests of this category are characterised by a lower produce some problems in terms of practicability and reliability,

As an interesting alternative, laboratory-based incremental tread- 
reproducibility because of tactical and motivational aspects. ${ }^{29}$ Other protocols such as the Montréal track test or the Vam-eval test were originally devised for running on a track following acoustic signals, providing an indirect estimation of $\mathrm{VO}_{2 \text { max. }}{ }^{31} 32$ However, the lack of specificity of this mode of assessment (ie, continuous running) is not reflective of the intermittent nature of team and racket sports.

During the past two decades, efforts have been made to develop discontinuous incremental field tests based on shuttleruns to improve the specificity of assessment modes. Their aim is to establish maximal aerobic power under acoustically controlled conditions for distance covered and running velocity. ${ }^{33-36}$ These tests are validated by $\mathrm{VO}_{2}$ measurements, and the estimated $\mathrm{VO}_{2 \max }$ can be predicted by gender-related and age-related equations. Since tests include accelerations, decelerations and changes of direction, they can be categorised as semispecific. The $20 \mathrm{~m}$ multistage shuttle test (MSST; ie, multistage fitness test, beep-test or Léger test) consists of $20 \mathrm{~m}$ shuttle runs performed at increasing speeds, until exhaustion, ${ }^{33} 34$ and has become a standard field test, being part of the regular test battery of different national tennis federations (US Tennis Association (USTA), Tennis Australia). ${ }^{19} 37$ However, based on the demands of intermittent sports, ${ }^{25}$ the relevance of these continuous tests has been questioned, leading to the development of more valid and reliable sport-specific tests like the Yo-Yo intermittent recovery (IR) and the 30-15 intermittent fitness tests (30-15IFT). ${ }^{35}$ The Yo-Yo IR tests consist of $2 \times 20 \mathrm{~m}$ shuttle runs at increasing speeds, interspersed with a $10 \mathrm{~s}$ period of active recovery (controlled by audio signals). Level 1 (Yo-Yo IR1) starts at a lower speed, which increases in speed being more moderate than for the level 2 (Yo-Yo IR2) test (IR1: $10 \mathrm{~km} / \mathrm{h}$, IR2: $13 \mathrm{~km} / \mathrm{h}$ ). The Yo-Yo IR1 test evaluates an individual's ability to repeat intermittent exercise with a higher aerobic component compared with the Yo-Yo IR2 test, which taxes the aerobic and anaerobic energy systems. ${ }^{35}$

In the $30-15 \mathrm{IFT},{ }^{36}$ participants run $40 \mathrm{~m}$ shuttles for $30 \mathrm{~s}$ at a given velocity interspersed with $15 \mathrm{~s}$ of active recovery; running velocity for the work bouts is progressively increased with each run $(0.5 \mathrm{~km} / \mathrm{h})$. Owing to reliability and accuracy of the final running speed measured for individualising players' training intensity, this protocol is becoming widely used when undertaking interval running conditioning in intermittent sports. $^{38} 39$

In tennis, the use of these semispecific field tests (MSST, Yo-Yo IR and 30-15IFT) seems to be a good recommendation although, to the best of our knowledge, there is almost no scientific information regarding their use in tennis-specific settings, and just some normative values for the MSST are offered from national tennis federations. ${ }^{19} 37$ Moreover, it has to be pointed out that, in all presented tests, the respective running distances, movement characteristics and muscle groups involved still offer considerable differences compared with the tennis-specific workload profile.

To close the remaining gap, tennis researchers endeavour to develop more specific protocols. Two major qualities seem to make the difference between a semispecific and a specific endurance test in tennis: (1) the use of the tennis court dimensions and (2) the combination of specific footwork and hitting actions. During the past decade, different protocols have been published with an acceptable accuracy under standardised conditions. ${ }^{7} 8$ 40-45 Weber and Hollmann ${ }^{45}$ were the first authors describing an incremental on-court exercise test for assessing aerobic power in tennis players. The particular component for the standardisation of this test was the use of a ball-throwing machine, which projected balls alternatively to the right and the left corners of the baseline. Players had to hit alternating forehands and backhands in a prescribed pattern (ie, ball velocity, flying height and landing points). ${ }^{40} 45$ The intensity of the incremental test protocol is controlled by adjusting ball frequency (figure 2).

Based on this initial approach, and with some methodological differences, several test protocols assessing various physiological and skill performance criteria have been developed, all of them using a ball-throwing machine, ${ }^{41-44}$ although most of them require expensive equipment (ie, ball machine, radar measurements). Moreover, the underlying testing criteria (rhythm, direction and velocity of the ball feeding) and player movement characteristics (strokes, running details) are difficult to standardise. Thus, they are not routinely used and no reliable and representative comparisons between tennis populations can be made. ${ }^{29}$

To enhance reproducibility and practicability (ie, no expensive equipment is required), two different approaches have been published (the Girard Test and the Hit \& Turn Test). ${ }^{78} 46$ Both protocols follow an incremental protocol to exhaustion, including tennis footwork and stroke simulation, with movement velocities and directions controlled by visual or acoustic feedback. ${ }^{7}{ }^{8}$ Test stages are of $40-50 \mathrm{~s}$ in duration and interspersed by $10-20 \mathrm{~s}$ of rest (figure 3), with some differences in the protocols. Running direction, movement technique and stroke position are more variable and partly uncertain during the Girard Test compared with the Hit \& Turn Test. This ensures a closer approach to real tennis but complicates test preparation and execution. In both cases, it should be emphasised that stroke quality is far removed from reality and individual differences exist. This has to be considered, since it was shown that the upper limb work contributes considerably to the
Figure 2 Schematic setting for a tennis-specific endurance field test. ${ }^{42} 4445$

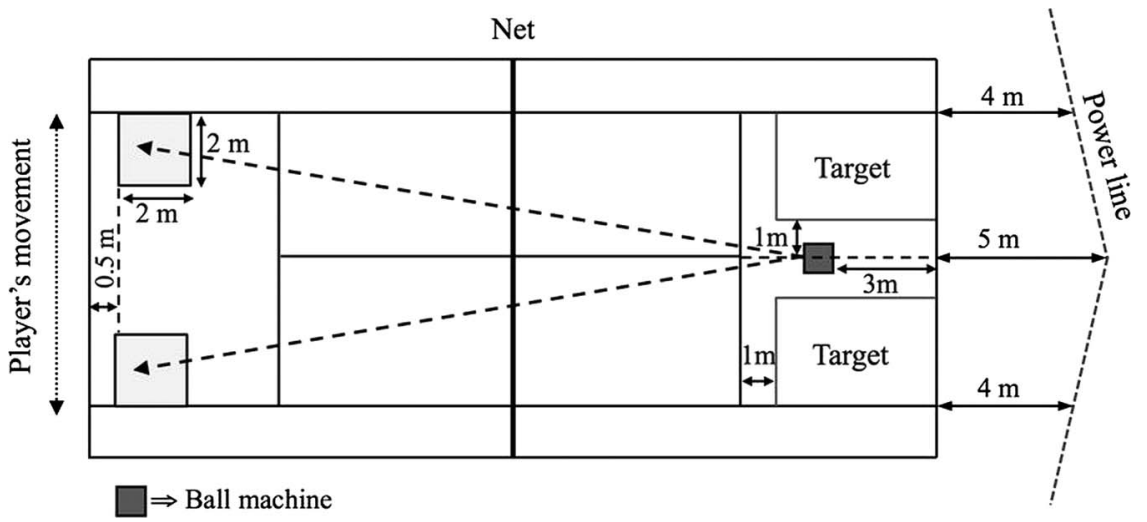


Figure 3 Progressive test design with the beep time intervals. ${ }^{8} \mathrm{BH}$, backhand; $\mathrm{FH}$, forehand.

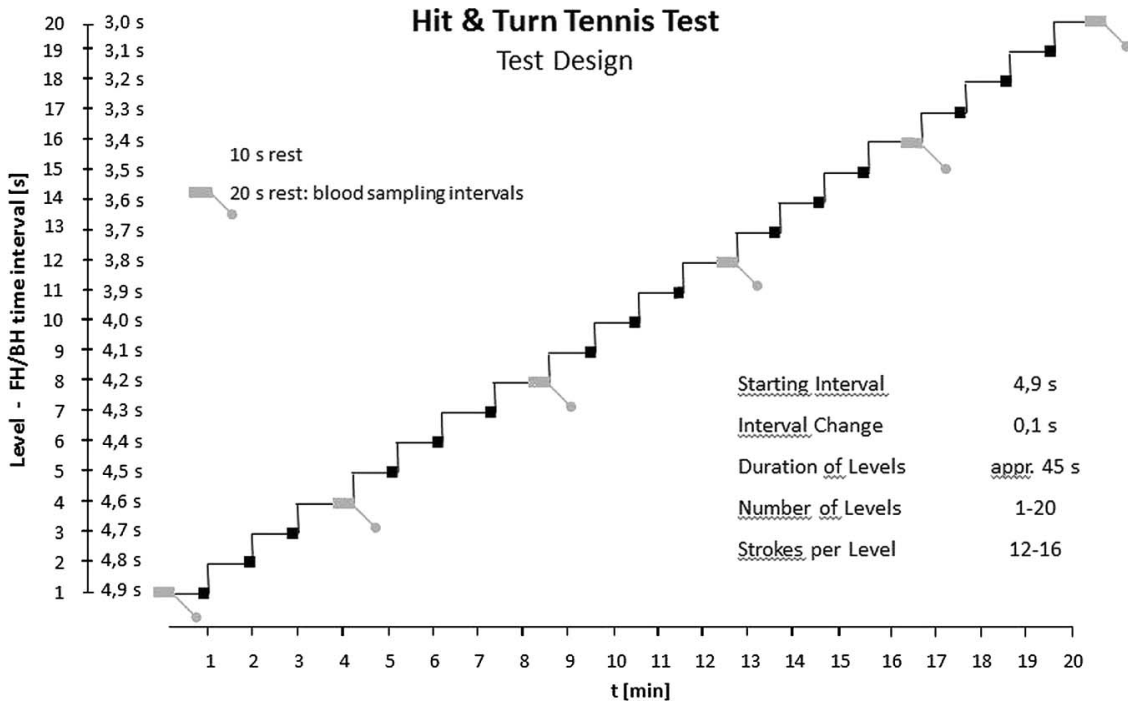

overall energetic demand in tennis. ${ }^{47}$ Regarding the practical use of these tests, the Hit \& Turn Test already offers age-related and sex-related normative values (see tables 1 and 2). ${ }^{21}$

\section{Anaerobic endurance testing}

Since the direct measurement of anaerobic ATP production is difficult, several indirect methods of measuring anaerobic ATP turnover have been developed, including the measurements of (1) muscle metabolites by muscle biopsy, (2) blood La production during supra-maximal exercise, (3) the maximum accumulated oxygen deficit (MAOD) and (4) the amount of work or power output during short-duration maximal exercise. ${ }^{48}$ Additional insights into ATP and phosphocreatine (PCr) muscle metabolism can be obtained through the use of 31P-magnetic resonance spectroscopy. ${ }^{49}$ Although the MAOD test has been accepted as the gold standard to determine anaerobic capacity, ${ }^{50}$ no information is available regarding its use as part of a tennis endurance performance assessment.

\section{Laboratory tests}

Owing to its practicability, in most sports, the assessment of peak power output determined by the $30 \mathrm{~s}$ Wingate Test has been used as a basic anaerobic test, ${ }^{51}$ despite the knowledge that short-duration exercise tests $(<60 \mathrm{~s})$ are inadequate at exhausting anaerobic energy systems. ${ }^{48}$ Regarding its use in tennis, the validity of a cycling test should be questioned, ${ }^{52}$ especially considering that no correlation between the ranking and the maximal power and work output assessed by the $30 \mathrm{~s}$ Wingate Test was shown in elite junior female tennis players. ${ }^{53}$

The use of power output measurements with non-motorised treadmills seems to be a future option for intermittent sports, ${ }^{54-56}$ with protocols proposed including single or multiple sprints (eg, 6-10 consecutive $6-10 \mathrm{~s}$ sprints interspersed with $15-180 \mathrm{~s}$ recovery). ${ }^{57}$ However, to estimate the potential of non-motorised treadmill testing as a means of anaerobic laboratory assessment in tennis, research using different protocols is necessary.

\section{Field-based tests}

Classical anaerobic field tests include the step-running test, or the measure of maximal La production during one all-out sprint over an established distance (eg, 80,100 or $200 \mathrm{~m}) .^{58} 59$ However, a more specific approach for anaerobic testing consists in the measurement of repeated sprint ability (RSA). ${ }^{6-62}$ RSA is usually determined by using running protocols with several

Table 1 Example of the physical qualities assessed in the test battery used by the DTB as well as average values and SDs for U12 to U18 male players

\begin{tabular}{|c|c|c|c|c|c|}
\hline \multicolumn{6}{|l|}{ Male players } \\
\hline Qualities & Measurements & U12 (n=102) & U14 (n=229) & U16 $(n=137)$ & U18 (n=77) \\
\hline Anthropometry & $\begin{array}{l}\text { Height }(\mathrm{cm}) \\
\text { Weight }(\mathrm{kg}) \\
\text { BMI }\end{array}$ & $\begin{array}{r}149.6 \pm 7.8 \\
38.5 \pm 5.8 \\
17.1 \pm 1.4\end{array}$ & $\begin{array}{r}160.5 \pm 8.3 \\
47.2 \pm 7.9 \\
18.2 \pm 1.7\end{array}$ & $\begin{array}{r}174.1 \pm 7.4 \\
60.6 \pm 8.7 \\
19.9 \pm 1.9\end{array}$ & $\begin{array}{r}181.5 \pm 5.7 \\
71.9 \pm 7.3 \\
21.8 \pm 1.5\end{array}$ \\
\hline Strength and power & $\begin{array}{l}\text { Grip strength* }(\mathrm{kg}) \\
\mathrm{CMJ}(\mathrm{cm}) \\
\text { Medicine ball throwt }(\mathrm{cm}) \\
\text { Service velocity }(\mathrm{km} / \mathrm{h})\end{array}$ & $\begin{array}{c}21.6 \pm 3.8 \\
28.9 \pm 3.8 \\
524.2 \pm 81.7 \\
121.5 \pm 9.3\end{array}$ & $\begin{array}{l}28.3 \pm 6.2 \\
31.0 \pm 4.2 \\
635.3 \pm 119.7 \\
137.7 \pm 11.9\end{array}$ & $\begin{array}{l}39.7 \pm 8.9 \\
36.5 \pm 4.4 \\
875.2 \pm 152.8 \\
160.1 \pm 12.2\end{array}$ & $\begin{array}{c}49.8 \pm 7.7 \\
39.9 \pm 4.1 \\
1090.1 \pm 163.2 \\
176.9 \pm 10.8\end{array}$ \\
\hline Speed and agility & $\begin{array}{l}10 \mathrm{~m}(\mathrm{~s}) \\
20 \mathrm{~m}(\mathrm{~s}) \\
\text { Shuttle sprint FH (s) } \\
\text { Shuttle sprint BH (s) }\end{array}$ & $\begin{array}{l}2.04 \pm 0.07 \\
3.64 \pm 0.19 \\
3.06 \pm 0.12 \\
3.16 \pm 0.16\end{array}$ & $\begin{array}{l}1.96 \pm 0.11 \\
3.47 \pm 0.16 \\
2.96 \pm 0.16 \\
3.08 \pm 0.17\end{array}$ & $\begin{array}{l}1.85 \pm 0.11 \\
3.25 \pm 0.17 \\
2.77 \pm 0.14 \\
2.90 \pm 0.22\end{array}$ & $\begin{array}{l}1.77 \pm 0.11 \\
3.09 \pm 0.12 \\
2.72 \pm 0.14 \\
2.86 \pm 0.15\end{array}$ \\
\hline Endurance & Hit \& Turn Test (level) & $12.4 \pm 2.0$ & $14.1 \pm 2.0$ & $16.3 \pm 1.8$ & $17.7 \pm 1.8$ \\
\hline
\end{tabular}


Table 2 Example of the physical qualities assessed in the test battery used by the DTB as well as average values and SDs for U12 to U18 female players

\begin{tabular}{|c|c|c|c|c|c|}
\hline \multicolumn{6}{|l|}{ Female players } \\
\hline Qualities & Measurements & U12 (n=65) & U14 (n=149) & U16 (n=73) & U18 (n=37) \\
\hline Anthropometry & $\begin{array}{l}\text { Height }(\mathrm{cm}) \\
\text { Weight }(\mathrm{kg}) \\
\text { BMI }\end{array}$ & $\begin{array}{r}149.5 \pm 6.4 \\
38.1 \pm 6.4 \\
17.0 \pm 1.9\end{array}$ & $\begin{array}{r}160.5 \pm 6.9 \\
48.7 \pm 7.2 \\
18.8 \pm 1.8\end{array}$ & $\begin{array}{r}167.3 \pm 5.8 \\
57.5 \pm 6.7 \\
20.5 \pm 1.9\end{array}$ & $\begin{array}{r}171.5 \pm 6.5 \\
63.4 \pm 6.3 \\
21.5 \pm 1.7\end{array}$ \\
\hline Strength and power & $\begin{array}{l}\text { Grip strength* }(\mathrm{kg}) \\
\mathrm{CMJ}(\mathrm{cm}) \\
\text { Medicine ball throwt }(\mathrm{cm}) \\
\text { Service velocity }(\mathrm{km} / \mathrm{h})\end{array}$ & $\begin{array}{c}20.6 \pm 4.1 \\
28.6 \pm 4.0 \\
505.5 \pm 92.1 \\
112.2 \pm 9.2\end{array}$ & $\begin{array}{c}27.4 \pm 5.2 \\
29.8 \pm 3.8 \\
611.2 \pm 96.2 \\
127.8 \pm 10.6\end{array}$ & $\begin{array}{l}32.1 \pm 4.0 \\
31.1 \pm 3.6 \\
709.8 \pm 105.7 \\
142.3 \pm 10.3\end{array}$ & $\begin{array}{l}35.7 \pm 5.0 \\
31.1 \pm 3.9 \\
788.3 \pm 124.8 \\
150.9 \pm 8.3\end{array}$ \\
\hline Speed and agility & $\begin{array}{l}10 \mathrm{~m}(\mathrm{~s}) \\
20 \mathrm{~m}(\mathrm{~s}) \\
\text { Shuttle sprint FH (s) } \\
\text { Shuttle sprint BH (s) }\end{array}$ & $\begin{array}{l}2.03 \pm 0.09 \\
3.61 \pm 0.14 \\
3.11 \pm 0.13 \\
3.21 \pm 0.16\end{array}$ & $\begin{array}{c}1.98 \pm 0.08 \\
3.5 \pm 0.14 \\
2.99 \pm 0.13 \\
3.12 \pm 0.15\end{array}$ & $\begin{array}{l}1.96 \pm 0.15 \\
3.41 \pm 0.14 \\
2.88 \pm 0.11 \\
3.03 \pm 0.17\end{array}$ & $\begin{array}{l}1.96 \pm 0.09 \\
3.38 \pm 0.19 \\
2.88 \pm 0.13 \\
3.05 \pm 0.14\end{array}$ \\
\hline Endurance & Hit \& Turn Test (level) & $11.8 \pm 2.0$ & $12.7 \pm 1.9$ & $13.8 \pm 1.9$ & $14.3 \pm 1.8$ \\
\hline
\end{tabular}

*Dominant hand.

tOverhead medicine ball.

BH, backhand; BMI, body mass index; CMJ, countermovement jump; DTB, German Tennis Federation; FH, forehand.

repeated short sprints (eg, 6-10×5-6 s or 20-40 m) interspersed with brief recovery periods (eg, 10-30 s), ${ }^{25} 61$ although protocols can also be conducted in a laboratory setting (ie, bike ergometer). Since multiple metabolic and neuromuscular factors (ie, PCr availability, anaerobic glycolytic flow, etc) are responsible for RSA, a clear classification of RSA as an anaerobic field test is questioned. ${ }^{61}$ Assessments of RSA generally provide two performance indices: (1) the overall test performance (eg, total sprint time or work (s or $\mathrm{kJ}$ ); mean sprint time or power (s or $\mathrm{W})$; best sprint time (s)) and (2) percentage decrement scores. ${ }^{25}$ Some protocols calculate a fatigue index (ie, change from the first to the last or from the best to the worst sprint); however, the percentage decrement score (ie, ((mean sprint time/best sprint time) $\times 100)-100$ ) is a more valid and reliable measure of fatigue for RSA. ${ }^{60}$ It has been suggested that anaerobic power scores are major determinants of overall RSA performance (eg, repeated mean power or speed) and that aerobic capacity is closely associated with the percentage decrement scores between the sprints. ${ }^{60}$

The use of RSA tests in tennis is scarce, with just some information about different protocols and normative values. Tennis Australia recommends $10 \times 20 \mathrm{~m}$ with $20 \mathrm{~s}$ rest, with two performance scores: the real accumulated sprint time in seconds and the percent decrement score. ${ }^{37} \mathrm{~A}$ more tennis-specific test, including $10 \times \sim 20 \mathrm{~m}$ shuttle sprints, was used in a recent study, ${ }^{63}$ with mean time and per cent decrement as the main performance measurements.

In the context of RSA testing, several aspects should be highlighted. Athletes usually develop pacing strategies throughout the test and, therefore, potentially do not exert a maximal effort. $^{2}$ Furthermore, the performance score selection seems to be difficult, with the total accumulated sprint time being more reliable than the decrement scores. ${ }^{64}$ Since the total accumulated sprint time is almost perfectly correlated with the best sprint time, ${ }^{65}$ a simple $20 \mathrm{~m}$ sprint may be enough, being more practical and less demanding for the athletes. However, more research is needed to clarify this issue.

\section{Strength and power testing}

The modern game of tennis has evolved to a current fast-paced, explosive sport based on strength and power. ${ }^{166} 67$ Maximal strength is defined as the result of force-producing muscles performing maximally, either in isometric or dynamic patterns during a single voluntary effort of a defined task. ${ }^{68}$ Power production is the product of force and velocity and is probably the most important factor in determining success in many sports. Thus, the 'ability to generate force (strength)' is an integral part of power production and, therefore, may be a key component in determining athletic success. ${ }^{69}$ Moreover, strength and power can represent specific or independent qualities of neuromuscular performance and, therefore, can be assessed and trained independently. $^{70}$

\section{Laboratory tests}

Maximum strength tests

Isometric testing for maximum voluntary strength has been used in different contexts with a variety of testing protocols. Several hand-held dynamometers (ie, hip abduction, shoulder, hand, etc) or stationary machines (eg, bench press or squat machine), usually working with force transducers, are available to assess isometric strength (in Newtons $(\mathrm{N})$ ) in different muscle groups. $^{71-73}$ Isometric testing protocols are also used to measure the ability to develop force rapidly, referred to as the rate of force development, being an important performance indicator. $^{69}$ However, research has questioned the validity of isometric assessments, given poor correlations between isometric test outcomes and dynamic performance. ${ }^{74}$ In order to assess the asymmetry between the dominant and non-dominant hand in the tennis player, ${ }^{75} 76$ the handgrip strength measurement is widely used, due to its simplicity, low cost and technique reproducibility. ${ }^{77}$ In the past few years, age-related and sex-related normative values have been reported for tennis players (tables 1 and 2$).^{21}$

Dynamic strength can be assessed in a variety of ways using an assortment of testing equipment (ie, free weights or fixed resistance machines). Traditionally, performance-related changes in maximal voluntary dynamic strength capabilities have been assessed using one-repetition maximum (1RM; the maximal amount of weight that can be lifted in one repetition) test protocols. The use of free weights is usually the most accurate way in determining functional strength in a sport-specific context, ${ }^{78}$ as the athlete has a greater freedom of movement. However, such procedures may not be easy to control, as athletes need to be proficient in the movement patterns and able to handle maximal 
loads. Other measures such as the 3RM, 5RM, 10RM and the maximum number of repetitions that can be performed at a fixed resistance can also be determined, although it is important to take into account the body mass or using different formulas depending on the sport (ie, Wilks formula). ${ }^{79}$ The rationale for maximal tests is that an increase in maximal strength is usually connected with an improvement in relative strength and, therefore, with improvement of power abilities. ${ }^{68}$ In female tennis players, ball velocities of the serve, forehand and backhand strokes have been moderately correlated to $1 \mathrm{RM}$ military press, but not to bench press performance. ${ }^{15}$ This relationship between maximal strength and performance is also supported by jump test results, as well as sprint times over $10-30 \mathrm{~m}$ in other intermittent sports. ${ }^{2} 7880$ Although the $1 \mathrm{RM}$ is the standard for determining isotonic strength, determining 1RM values for large groups is very time consuming and has been suggested to expose those being tested to increased injury risk. Therefore, the use of single set tests in which 1RM values are predicted based on the number of repetitions performed with a submaximal weight has been recommended. ${ }^{81}$ The use of these measurements in tennis is scarce, with little information about different protocols as well as normative values extracted from some national tennis federations. ${ }^{37}$

\section{Isokinetic strength tests}

Isokinetic measurements, which are used to measure force/ torque outputs at a constant angular velocity throughout the test movement, and typically using open kinetic chain exercises, have been extensively utilised in the field of evaluation and rehabilitation of sports injuries. ${ }^{82}$ The rationale for their use is that several throwing motions like the tennis serve and groundstrokes are open kinetic chain movements of the upper extremities, and the use of open kinetic chain muscular strength assessments allow for isolation of particular muscle groups, commonly affected by pathological changes (eg, rotator cuff injuries). ${ }^{83}$ Moreover, isokinetic testing allows for obtaining unilateral strength ratios, bilateral comparisons or relative fatigue ratios in important sport-specific muscle groups (ie, external/ internal rotators). ${ }^{82}$ Although the majority of tennis studies that report isokinetic data used these measures to assess the effectiveness of training techniques rather than as a predictor of performance, ${ }^{84-87}$ several studies showed different correlations with performance. Perry et $a l^{88}$ found positive correlations between peak torque for different motions (ie, overhead, diagonal) and stroke velocity (ie, serve, forehand). Consistent with this, several studies showed that the trunk rotation and flexion strength of elite junior players were correlated with forehand and backhand medicine ball throwing distance, ${ }^{89}{ }^{90}$ while Cohen et $a l^{84}$ revealed a positive association between serving velocity and peak isokinetic elbow extension torque. However, other studies have observed low correlations between different leg, shoulder and wrist strength measures and serving speed in similar playing populations. ${ }^{91}$ The fact that most functional activities have angular velocities far exceeding the capabilities of isokinetic dynamometers suggest that isokinetic assessment techniques are only one part of the evaluation and, if necessary, rehabilitation process. Therefore, other strength measurements should be included in the testing procedures for tennis players. Moreover, the access to these technologies is difficult and expensive, making the testing process difficult.

\section{Power assessment}

Power is generally tested using isoinertial protocols with resistance loads. ${ }^{92}$ Squat jumps and countermovement jumps are commonly used for the lower body, while bench throws or bench pulls, with varying inertial loads, are used for the upper body. ${ }^{69}$ Assessments typically employ apparatus such as a Smith machine, with position transducers included into the device used to quantify mechanical power output (in N). The load at which peak power output is achieved, termed $\mathrm{P}_{\max }$, has been used as a performance measure in different intermittent sports. Values appear to relate only to the training movement tested and more related to power-based sports such as rugby or American football. ${ }^{92}$

\section{Field-based tests}

The vertical jump is a common action in most sports and is biomechanically similar to various acceleration and game-related dynamic movements. It would, therefore, appear valid to include some form of vertical-jump assessment to evaluate explosive power in tennis. Assessments can be carried out in the laboratory, if kinetic measurements are needed (ie, with a force platform), although in terms of practicability, these tests are usually conducted in the field using contact mats to obtain basic measurements like contact and flying times. The strong correlations observed between sprint times (eg, 10 and $20 \mathrm{~m}$ sprints) and vertical jumps (eg, power during countermovement jump and drop jumps) in previous research ${ }^{15} 93$ underline the importance of muscle strength and power in the lower extremities to produce explosive actions in tennis players. ${ }^{67}$

Regarding upper-body power, medicine ball tests (ie, overhead throw; figure 4) seem to be useful for tennis players, as they show high external validity, because they involve the coordination of body segments (ie, kinetic chain) and allow generation, summation, transfer and regulation of forces from the lower body to the upper body, which is similar to tennis strokes. ${ }^{94}$ Moreover, previous research showed significant correlations between ball toss and strength (ie, isokinetic trunk rotation; individual values of velocity at $30 \%$ of $1 \mathrm{RM}$ bench press), ${ }^{95} 96$ as well as serve velocity, ${ }^{97}$ suggesting that these tests are fundamental indicators of whole body explosive power regardless of throwing technique. ${ }^{96}$ Thus, the use of vertical jump tests and medicine ball throws has been part of the regular testing of tennis players in different national tennis associations $^{21} 37$ (tables 1 and 2).

\section{Tennis-specific tests}

Since sport-specific technical skills are predominant factors (eg, stroke skills) in tennis, the most appropriate tests seem to be those measuring serve and groundstrokes velocities. ${ }^{98}$ In this regard, the tennis serve velocity test appears to show high external validity in terms of its relationship with tennis functional performance, as it is a basic action relying on multiple body segments to produce power through properly timed rotations and complex coordinated muscular activations. ${ }^{94}$ Moreover, it has been considered the most stable and predictable measure of on-court tennis performance, ${ }^{88} 66$ with recent data showing medium-to-large correlations with individual rankings in male and female players (ie, from U14 to U18). ${ }^{21} 97$ Previous research also showed reliable and valid tests aiming to assess performance of groundstrokes in low-level to intermediate-level tennis players. ${ }^{99}$ Figure 5 shows the representation of a serve performance test. ${ }^{98} 100101$ Serve velocity is measured with a radar gun positioned behind the server. The highest speed recorded is used for analysis. The intertrial reliability for serve velocity ranges between $3 \cdot 2 \%$ and $3 \cdot 5 \% .{ }^{98} 100$ Serve accuracy is determined by counting the number of times the ball landed within the designated target perimeter. Participants serve from the 
1

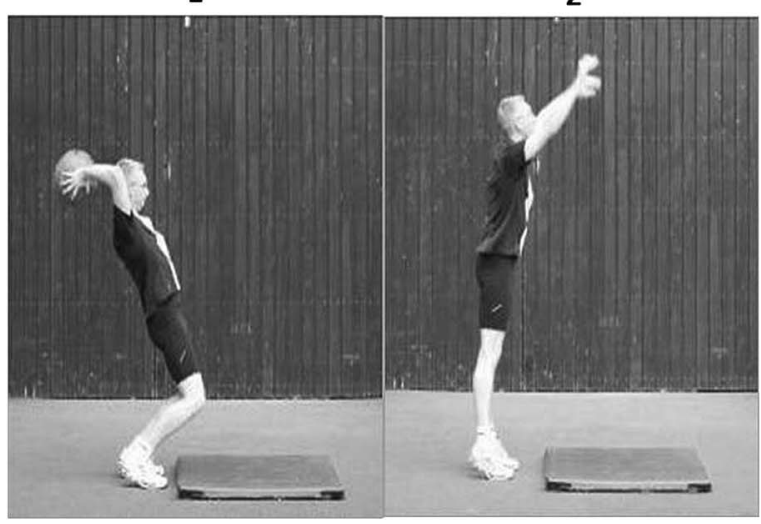

3

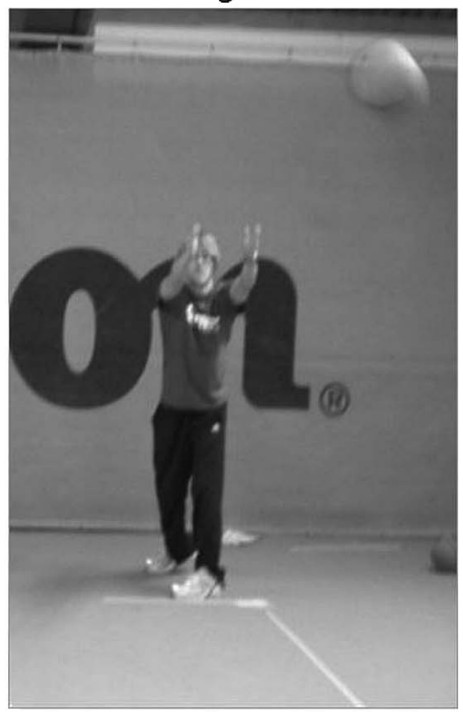

Figure 4 Examples of medicine ball throws (overhead throw (pictures 1 and 2) and forehand side throw (picture 3)).

deuce court and are instructed to 'serve first serves flat and down the T' (centre line). Shots landing within target areas are ranked according to a 3,2 , 1, scoring system. Balls landing outside the perimeter of the target areas (ie, errors) received a score of 0 . A total score is recorded for each trial.

\section{Speed and agility testing}

In tennis, speed comprises the ability to move at high velocity in a variety of directions, and often not in a straight line. Players not only need to be exceptional movers in a linear direction (ie, acceleration), but also laterally and multidirectionally. Speed has been defined as the rate of change of distance with respect to time, whereas acceleration is the rate of change in speed with respect to time. ${ }^{69}$ Owing to constant changes of direction, players are not able to achieve maximal running speeds (ie, obtained between 30 and $60 \mathrm{~m}$ in a straight line sprint). Therefore, acceleration and deceleration seem to be fundamental for tennis players.

\section{Field-based tests}

Linear sprints

Owing to its good reproducibility, the $20 \mathrm{~m}$ sprint test, with splits at 5 and $10 \mathrm{~m}$, is used as a general measure of linear acceleration and speed. Speed scores over $5 \mathrm{~m}$ have been employed to measure 'first-step quickness', while split times over 10-15 m are often used to evaluate acceleration ability. ${ }^{69}$ In tennis,

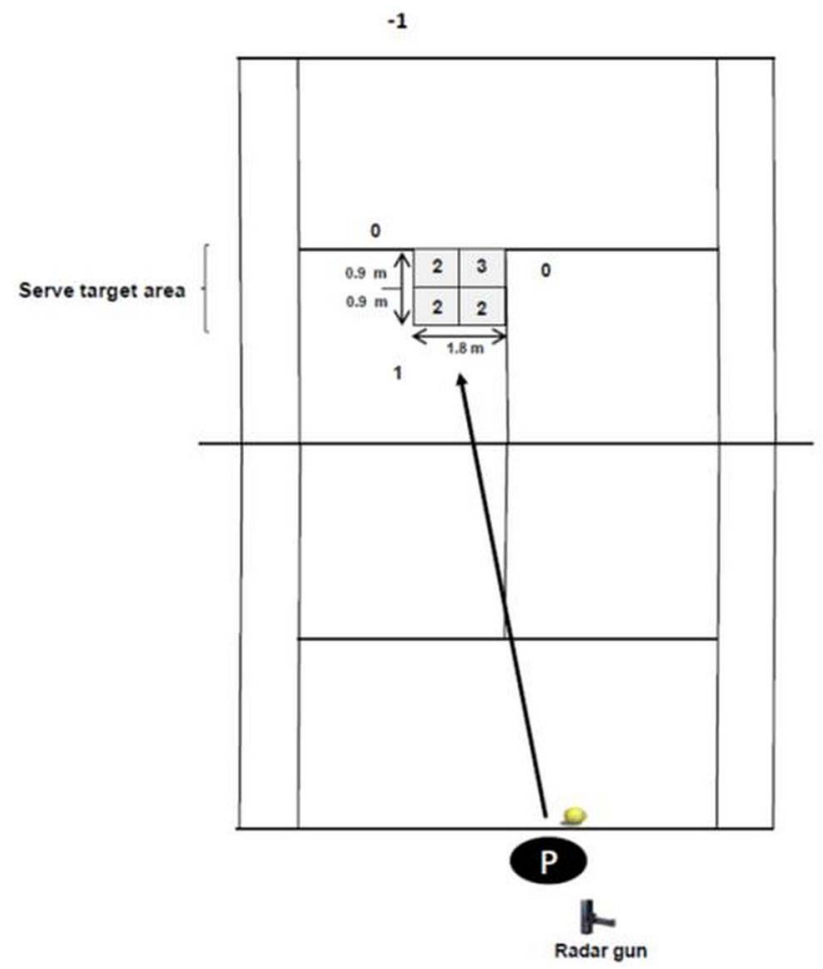

Figure 5 A schematic representation of the serve performance test and target area dimensions.

although the distances of 5 and $10 \mathrm{~m}$ are most specific to those covered in any one effort during a match, the evaluation of speed over $20 \mathrm{~m}$ can be informative ${ }^{37}$ (tables 1 and 2). The $20 \mathrm{~m}$ sprint test is usually included in the regular testing of national federations. ${ }^{21} 37$ Assessments are conducted using electronic timing gates, as they offer higher degrees of accuracy and reliability than stopwatch-recorded times.

Agility assessment

'Agility' is defined as a rapid whole-body movement with change of velocity or direction in response to a stimulus. ${ }^{102}$ Previous research showed that straight-line sprinting and change of direction tests typically show a limited statistical relationship, ${ }^{103}$ suggesting that acceleration, maximum speed and change of direction are distinct and separate abilities. Furthermore, correlations between measures of these abilities decrease markedly when any sport skill component is incorporated into the agility test. ${ }^{102} \mathrm{~A}$ wide variety of tests that measure change of direction ability are employed in different sports and could be used in tennis. Protocols differ in terms of complexity and duration. ${ }^{104}$ The tests which are considered the most valid for use in intermittent sports are the '5-0-5 test', in which the player turns once to sprint $5 \mathrm{~m}$ back to the start line, and the 'Illinois agility test', that features multiple slalom cuts through cones and $180^{\circ}$ turns. ${ }^{102}$ Both tests show positive correlations with acceleration measurements. ${ }^{105} \mathrm{~A}$ common test used in tennis as a measure of agility is the 'hexagon test', in which participants have to jump (double-leg hopping) from the centre of an hexagon drawn on the ground, over each side and back to the centre. ${ }^{106}$ Although it is reliable, there is no scientific information about its relationship with other agility tests, as well as with general speed measurements.

Since tennis is a complex sport in terms of movements and there are only a few studies analysing speed and agility 


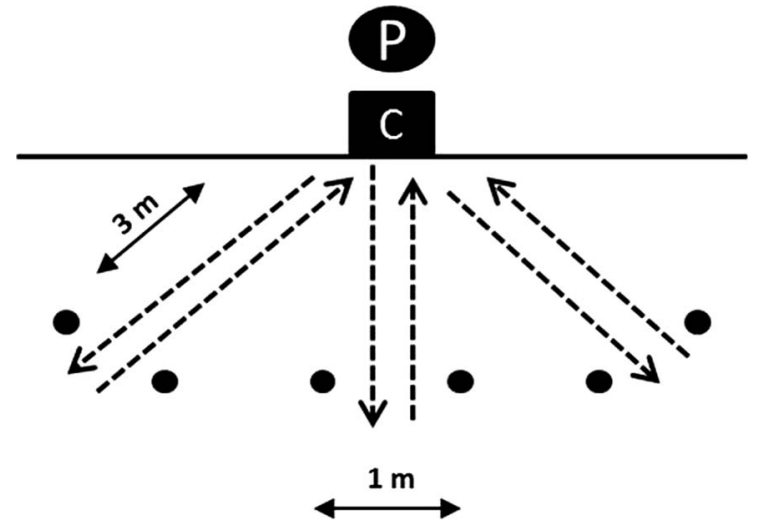

Figure 6 Planned and reactive agility test setup from Cooke et al. ${ }^{108}$ Light cells: $\mathrm{C}$, contact mat; $\mathrm{P}$, player.

components in tennis players, it is difficult to present specific tests. Change of direction tests have been modified to incorporate a simple reaction component to the movement task, so that the movement is executed in response to an external cue. The time recorded by the athlete on tests of this type represents a combination of reaction time and the time taken to complete the movement task. ${ }^{107}$ Cooke et $a l^{108}$ designed a test using an electronic timing system with programmable light stimuli in which the athlete had to move as quickly as possible from the baseline to three different gates in reaction to light signals (figure 6). A contact mat acted as a switch turning on the light on a random gate. On reaching the gate, the player was instructed to step over a line marker placed $30 \mathrm{~cm}$ beyond the gate and then return to the contact mat and repeat for a total of three gates.

More recently, Ulbricht et $a l^{21}$ designed a tennis-specific sprint test (figure 7) with the use of a twofold signal panel with

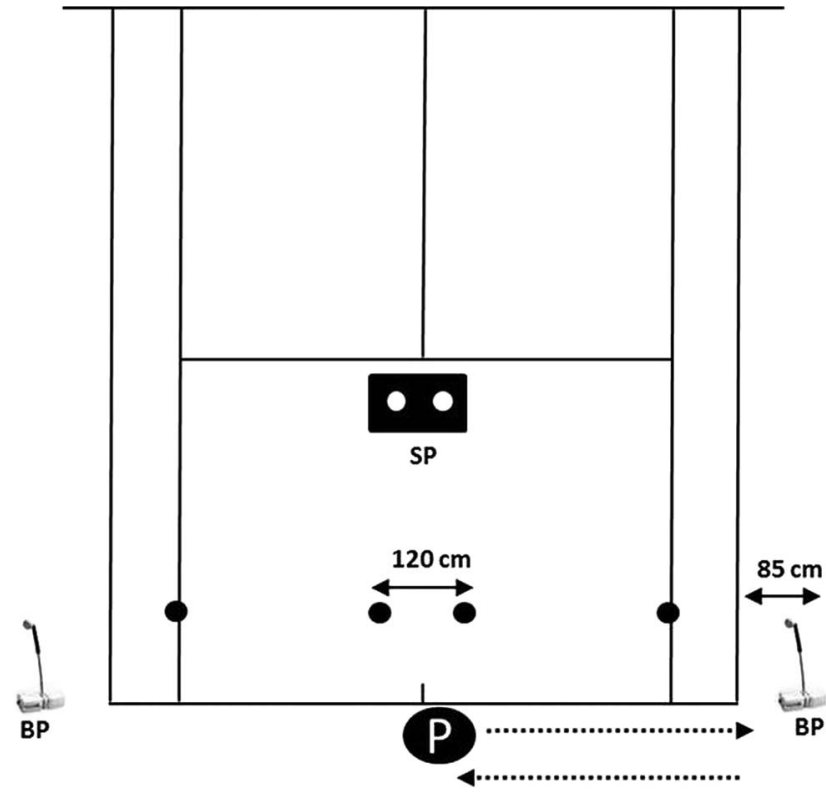

Figure 7 Tennis-specific sprint test. ${ }^{21}$ Light cells: BP, ball pendulum; P, player; SP, signal panel.

two light-emitting diodes (right-left). The player stands with his racket in a frontal position in the middle of the baseline. By activating one diode of the signal panel, the time is initiated, and players turn and run in a straight line to the prescribed corner, perform a stroke simulation against a ball pendulum and return to the initial position. Each player performs two maximal repetitions to each side, interspersed with $90 \mathrm{~s}$ rest of passive recovery and the fastest time achieved is recorded. The intraclass correlation coefficient obtained for this test was $0.94 .^{21}$

Table 3 Reference values based on the percentiles established for male players participating in the DTB testing

\begin{tabular}{|c|c|c|c|c|c|c|c|c|c|}
\hline \multicolumn{10}{|l|}{ Male players } \\
\hline & GS (kg) & MB (cm) & CMJ $(\mathrm{cm})$ & SV (km/h) & $10 \mathrm{~m}(\mathrm{~s})$ & $20 \mathrm{~m}(\mathrm{~s})$ & $\operatorname{SpF}(\mathrm{s})$ & SpB (s) & H\&T (level) \\
\hline \multicolumn{10}{|l|}{ U12 } \\
\hline Needs improvement & $<22$ & $<520$ & $<29.1$ & $<130$ & $>2.05$ & $>3.62$ & $>3.07$ & $>3.16$ & $<13$ \\
\hline Average & $22-23$ & $520-540$ & $29.1-29.9$ & 130-132 & $2.05-2.03$ & $3.62-3.59$ & $3.07-3.02$ & $3.16-3.13$ & 13-13.5 \\
\hline Good & $23-25.2$ & $540-602$ & $29.9-32.3$ & $132-138$ & $2.03-1.96$ & $3.59-3.48$ & $3.02-2.95$ & $3.13-3.08$ & $13.5-14.9$ \\
\hline Excellent & $>25.2$ & $>602$ & $>32.3$ & $>138$ & $<1 . .96$ & $<3.48$ & $<2.95$ & $<3.08$ & $>14.9$ \\
\hline \multicolumn{10}{|l|}{ U14 } \\
\hline Needs improvement & $<27$ & $<640$ & $<31$ & $<143$ & $>1.97$ & $>3.47$ & $>2.94$ & $>3.07$ & $<14$ \\
\hline Average & $27-29$ & $640-670$ & $31-32.1$ & 143-146 & $1.97-1.94$ & $3.47-3.42$ & $2.94-2.91$ & $3.07-3.04$ & $14-14.5$ \\
\hline Good & 29-33 & $670-729$ & $32.1-34.7$ & $146-154$ & $1.94-1.89$ & $3.42-3.34$ & $2.91-2.83$ & $3.04-2.96$ & $14.5-15.9$ \\
\hline Excellent & $>33$ & $>729$ & $>34.7$ & $>154$ & $<1.85$ & $<3.34$ & $<2.83$ & $<2.96$ & $>15.9$ \\
\hline \multicolumn{10}{|l|}{ U16 } \\
\hline Needs improvement & $<40$ & $<890$ & $<36.5$ & $<169$ & $>1.85$ & $>3.24$ & $>2.76$ & $>2.92$ & $<16.9$ \\
\hline Average & $40-43$ & $890-920$ & $36.5-37.6$ & 169-172 & $1.85-1.82$ & $3.24-3.22$ & $2.76-2.73$ & $2.92-2.87$ & 16.9-17.1 \\
\hline Good & $43-49$ & 920-1004 & $37.6-39.4$ & $172-179$ & $1.82-1.78$ & $3.22-3.11$ & $2.73-2.65$ & $2.87-2.80$ & 17.1-18 \\
\hline Excellent & $>52$ & $>1004$ & $>39.4$ & $>179$ & $<1.78$ & $<3.11$ & $<2.65$ & $<2.80$ & $>18$ \\
\hline \multicolumn{10}{|l|}{ U18 } \\
\hline Needs improvement & $<50$ & $<1080$ & $<40.1$ & $<184$ & $>1.78$ & $>3.08$ & $>2.72$ & $>2.84$ & $<18$ \\
\hline Average & $50-53$ & 1080-1140 & $40.1-41.3$ & 184-186 & $1.78-1.76$ & $3.08-3.05$ & $2.72-2.67$ & $2.84-2.79$ & 18-18.6 \\
\hline Good & $53-58$ & $1140-1260$ & $41.3-42$ & 186-193.2 & $1.76-1.71$ & $3.05-2.98$ & $2.67-2.58$ & $2.79-2.70$ & 18.6-19.4 \\
\hline Excellent & $>58$ & $>1260$ & $>42$ & $>193.2$ & $<1.71$ & $<2.98$ & $<2.58$ & $<2.70$ & $>19.4$ \\
\hline
\end{tabular}

CMJ, countermovement jump; DTB, German Tennis Federation; GS, grip strength dominant hand; H\&T, Hit and Turn; MB, overhead medicine ball throw (2 kg); SPb, shuttle sprint to the backhand; SPf, shuttle sprint to the forehand; SV, serve velocity. 
Table 4 Reference values based on the percentiles established for female players participating in the DTB testing

\begin{tabular}{|c|c|c|c|c|c|c|c|c|c|}
\hline \multicolumn{10}{|l|}{ Female players } \\
\hline & GS (kg) & $\mathrm{MB}(\mathrm{cm})$ & CMJ $(\mathrm{cm})$ & SV (km/h) & $10 \mathrm{~m}(\mathrm{~s})$ & $20 \mathrm{~m}(\mathrm{~s})$ & SpF (s) & $\mathrm{SpB}(\mathrm{s})$ & H\&T (level) \\
\hline \multicolumn{10}{|l|}{ U12 } \\
\hline Needs improvement & $<21.5$ & $<520$ & $<27.9$ & $<120$ & $>2.03$ & $>3.61$ & $>3.11$ & $>3.22$ & $<12$ \\
\hline Average & $21.5-22$ & $520-538$ & 27.9-29.5 & $120-123$ & $2.03-2.01$ & $3.61-3.57$ & $3.11-3.06$ & $3.22-3.17$ & $12-12.4$ \\
\hline Good & $22-24$ & $538-570$ & $29.5-32.3$ & $123-126$ & $2.01-1.96$ & $3.57-3.50$ & $3.06-2.98$ & $3.17-3.12$ & $12.4-13.5$ \\
\hline Excellent & $>24$ & $>570$ & $>32.3$ & $>126$ & $<1.96$ & $<3.50$ & $<2.98$ & $<3.12$ & $>13.5$ \\
\hline \multicolumn{10}{|l|}{ U14 } \\
\hline Needs improvement & $<27$ & $<610$ & $<29.8$ & $<136$ & $>1.99$ & $>3.50$ & $>2.99$ & $>3.12$ & $<13$ \\
\hline Average & $27-29$ & $610-646$ & $29.8-30.5$ & $136-139$ & 1.99-1.96 & $3.50-3.45$ & $2.99-2.92$ & $3.12-3.08$ & 13-13.4 \\
\hline Good & $29-32$ & $646-710$ & $30.5-33$ & $139-145$ & $1.96-1.91$ & $3.45-3.38$ & $2.92-2.87$ & $3.08-2.99$ & $13.4-14.6$ \\
\hline Excellent & $>32$ & $>710$ & $>33$ & $>145$ & $<1.91$ & $<3.38$ & $<2.87$ & $<2.99$ & $>14.6$ \\
\hline Needs improvement & $<33$ & $<720$ & $<31.7$ & $<152$ & $>1.95$ & $>3.40$ & $>2.87$ & $>3.01$ & $<14$ \\
\hline \multicolumn{10}{|l|}{ U16 } \\
\hline Average & $33-33.6$ & $720-740$ & $31.7-32.6$ & $152-153.2$ & $1.95-1.92$ & $3.40-3.36$ & $2.87-2.85$ & $3.01-2.98$ & $14-14.6$ \\
\hline Good & $33.6-36$ & $740-810$ & $32.6-34.2$ & $153.2-161$ & $1.92-1.88$ & $3.36-3.29$ & $2.85-2.78$ & $2.98-2.90$ & $14.6-16$ \\
\hline Excellent & $>36$ & $>810$ & $>34.2$ & $>161$ & $<1.88$ & $<3.29$ & $<2.78$ & $<2.90$ & $>16$ \\
\hline Needs improvement & $<36$ & $<810$ & $<31$ & $<157.5$ & $>1.95$ & $>3.37$ & $>2.86$ & $>3.00$ & $<15$ \\
\hline \multicolumn{10}{|l|}{ U18 } \\
\hline Average & $36-38$ & $810-830$ & $31-32.3$ & $157.5-160$ & $1.95-1.93$ & $3.37-3.33$ & $2.86-2.82$ & $3.00-2.98$ & $15-15.3$ \\
\hline Good & $38-40$ & $830-940$ & $32.3-35.4$ & $160-165.2$ & $1.93-1.87$ & $3.33-3.24$ & $2.82-2.75$ & $2.98-2.93$ & $15.3-16.8$ \\
\hline Excellent & $>40$ & $>940$ & $>35.4$ & $>165.2$ & $<1.87$ & $<3.24$ & $<2.75$ & $<2.93$ & $>16.8$ \\
\hline
\end{tabular}

CMJ, countermovement jump; DTB, German Tennis Federation; GS, grip strength dominant hand; H\&T, Hit and Turn; MB, overhead medicine ball throw (2 kg); SPb, shuttle sprint to the backhand; SPf, shuttle sprint to the forehand; SV, serve velocity.

\section{Musculoskeletal testing}

General musculoskeletal assessment protocols comprise static measurements and clinical examinations of joint integrity and ROM (eg, passive assessment). ${ }^{23}$ These assessments are widespread practice with the dual goal of injury prevention and performance enhancement. In general, tests of ROM and muscle flexibility are recommended to identify players at risk of muscle strain injury. ${ }^{23}$ Since injuries in tennis can involve all the areas of the body, the application and use of a comprehensive musculoskeletal examination using a series of tests throughout the entire body is recommended. ${ }^{12}{ }^{109}$ The USTA Sport Science Committee developed a test battery (High Performance Profile) which was recommended for use by competitive players, although there are no published normative values yet. ${ }^{23}$ The high performance profile comprises 10 tests, which have been shown to be valid and reliable in athletes (eg, shoulder internal and external ROM at $90^{\circ}$ abduction, straight leg raise test). ${ }^{110-113}$

In recent years, movement-based protocols have become more popular, together with the use of standard musculoskeletal assessments. The Functional Movement Screen (FMS) is a relatively new tool that attempts to address multiple movement factors, with the goal of predicting general risk of musculoskeletal conditions and injuries. ${ }^{114} 115$ The FMS consists of seven fundamental movement component tests (ie, deep squat, in-line lunge and hurdle step) that are scored on a scale of $0-3$, with the sum creating a composite score ranging from 0 to 21 points. Based on recent research, ${ }^{116-118}$ FMS is found to show good reliability and appears to be a valid method to detect deficits in gross movement quality and identify movement asymmetries. However, to date, there are no published normative values

Table 5 Example of percentiles established for U14 male players based on the DTB test battery

\begin{tabular}{|c|c|c|c|c|c|c|c|c|c|c|c|c|}
\hline \multicolumn{13}{|c|}{ Physical tests } \\
\hline & Height (cm) & Weight (kg) & BMI & GS (kg) & $\mathrm{CMJ}(\mathrm{cm})$ & $\mathrm{MB}(\mathrm{cm})$ & SV (km/h) & $10 \mathrm{~m}(\mathrm{~s})$ & $20 \mathrm{~m}(\mathrm{~s})$ & $S p F(s)$ & $\mathrm{SpB}(\mathrm{s})$ & H\&T (level) \\
\hline \multicolumn{13}{|c|}{ Percentiles } \\
\hline 10 & 150.6 & 38.2 & 16.0 & 22.0 & 26.2 & 491.0 & 124.1 & 1.85 & 3.25 & 2.77 & 2.87 & 11.6 \\
\hline 20 & 153.2 & 40.3 & 16.6 & 23.0 & 27.3 & 530.0 & 127.8 & 1.89 & 3.34 & 2.83 & 2.96 & 12.8 \\
\hline 30 & 155.5 & 42.7 & 17.3 & 25.0 & 28.5 & 563.0 & 131.8 & 1.93 & 3.39 & 2.88 & 2.99 & 13.2 \\
\hline 40 & 157.5 & 44.1 & 17.7 & 26.0 & 29.7 & 600.0 & 134.7 & 1.94 & 3.42 & 2.91 & 3.04 & 14.0 \\
\hline 50 & 160.0 & 45.7 & 18,0 & 27.0 & 30.6 & 635.0 & 136.3 & 1.97 & 3.47 & 2.94 & 3.07 & 14.0 \\
\hline 60 & 161.8 & 47.7 & 18.5 & 28.0 & 32.0 & 668.0 & 138.0 & 1.99 & 3.51 & 2.99 & 3.11 & 14.7 \\
\hline 70 & 163.6 & 50.6 & 19.0 & 30.0 & 33.2 & 688.5 & 142.9 & 2.01 & 3.56 & 3.03 & 3.16 & 15.0 \\
\hline 80 & 167.5 & 53.3 & 19.7 & 33.0 & 34.6 & 718.0 & 146.8 & 2.04 & 3.60 & 3.09 & 3.21 & 15.6 \\
\hline 90 & 172.5 & 58.7 & 20.4 & 37.0 & 36.4 & 770.0 & 154.3 & 2.09 & 3.68 & 3.18 & 3.29 & 17.0 \\
\hline
\end{tabular}

BMI, body mass index; CMJ, countermovement jump; DTB, German Tennis Federation; GS, grip strength dominant hand; H\&T, Hit and Turn; MB, overhead medicine ball throw; SPb, shuttle sprint to the backhand; SPf, shuttle sprint to the forehand; SV, serve velocity. 
regarding the use of FMS with athletes, and only isolated studies provided data regarding young active population. ${ }^{119}$ This could help coaches interpret the raw data collected during testing and, therefore, future research is recommended to further refine and validate the FMT as a screening tool that can be used in multiple sporting settings, including tennis.

\section{Practical applications}

The use of a regular fitness testing in tennis provides framework for the development of an individualised database and a more efficient programme of the physical fitness training, especially in junior players. Based on the test selection criteria previously presented, tables 1 and 2 summarise the most appropriate tests for tennis players, with age and sex group average values of the test battery conducted by the German Tennis Federation (DTB) twice a year since $2009 .^{21} 97$ With the results obtained from the testing protocols and the normative values (tables 3 and 4), coaches and physical trainers can develop individual profiles of the players, based on age and sex group percentiles (table 5), with their respective strengths and weaknesses. This would lead to a more efficient design of physical training programmes, saving time for the tennis-specific training. ${ }^{21}$

Contributors JF-F and AF designed the review and wrote the manuscript. AU managed the literature search and tables/figures. All authors contributed to and have approved the final version of the manuscript.

\section{Competing interests None.}

Provenance and peer review Not commissioned; externally peer reviewed.

Open Access This is an Open Access article distributed in accordance with the Creative Commons Attribution Non Commercial (CC BY-NC 3.0) license, which permits others to distribute, remix, adapt, build upon this work non-commercially, and license their derivative works on different terms, provided the original work is properly cited and the use is non-commercial. See: http://creativecommons.org/ licenses/by-nc/3.0/

\section{REFERENCES}

1 Fernandez-Fernandez J, Sanz-Rivas D, Mendez-Villanueva A. A review of the activity profile and physiological demands of tennis match play. Strength Cond $J$ 2009;31:15-26

2 Svensson M, Drust B. Testing soccer players. J Sports Sci 2005:23:601-18.

3 Reilly $T$, Morris $T$, Whyte $G$. The specificity of training prescription and physiological assessment: a review. J Sports Sci 2009:27:575-89.

4 MacDougall JD, Wenger HA, Green HJ. eds Physiological testing of the high-performance athlete. Champaign, IL: Human Kinetics Books, 1991.

5 Bangsbo J. The physiology of soccer with special reference to intense intermittent exercise. Acta Physiol Scand Suppl 1994:619:1.

6 Hoff J. Training and testing physical capacities for elite soccer players. J Sports Sci 2005;23:573-82.

7 Girard 0, Chevalier R, Leveque $F$, et al. Specific incremental field test for aerobic fitness in tennis. Br J Sports Med 2006;40:791-6.

8 Ferrauti A, Kinner V, Fernandez-Fernandez J. The Hit \& Turn Tennis Test: an acoustically controlled endurance test for tennis players. J Sports SCi 2011;29:485-94.

9 Alricsson M, Harms-Ringdahl K, Werner S. Reliability of sports related functional tests with emphasis on speed and agility in young athletes. Scand J Med Sci Sports 2001:11:229-32.

10 Bangsbo J, Mohr M, Poulsen A, et al. Training and testing the elite athlete. J Exerc Sci Fitness 2006:4:1-13.

11 Stolen T, Chamari K, Castagna C, et al. Physiology of soccer: an update. Sports Med 2005:35:501-36

12 Kovacs MS. Tennis physiology: training the competitive athlete. Sports Med 2007:37:189-98.

13 Gabbett TJ. Science of rugby league football: a review. J Sports Sci 2005:23:961-76

14 Girard 0, Millet GP. Physical determinants of tennis performance in competitive teenage players. I Strength Cond Res 2009:23:1867-72.

15 Kraemer WJ, Hakkinen K, Triplett-Mcbride NT, et al. Physiological changes with periodized resistance training in women tennis players. Med Sci Sports Exerc 2003:35:157-68

16 Birrer R, Levine R, Gallippi L, et al. The correlation of performance variables in preadolescent tennis players. J Sports Med Phys Fitness 1986:26:137.
17 Kraemer WJ, Triplett NT, Fry AC, et al. An in-depth sports medicine profile of women college tennis players. J Sport Rehabil 1995;4:79-98.

18 Roetert E, Piorkowski $\mathrm{P}$, Woods $\mathrm{R}$, et al. Establishing percentiles for junior tennis players based on physical fitness testing results. Clin Sports Med 1995;14:1.

19 Roetert P, Ellenbecker TS. Complete conditioning for tennis. Human Kinetics Publishers, 2007

20 Buckeridge A, Farrow D, Gastin P, et al. Protocols for the physiological assessment of high-performance tennis players. Physiological tests for elite Athletes Australian Sports Commission. Champaign, IL: Human Kinetics, 2000.

21 Ulbricht A, Fernandez-Fernandez J, Ferrauti A. Conception for fitness testing and individualized training programs in the German Tennis Federation. Sports Orthopaedics and Traumatology 2013;29:180-92.

22 Kovacs MS. Applied physiology of tennis performance. Br J Sports Med 2006:40:381-5

23 Ellenbecker T, De Carlo M, DeRosa C. Effective functional progressions in sport rehabilitation. Human Kinetics, 2009.

24 Fernandez J, Mendez-Villanueva A, Pluim B. Intensity of tennis match play. $\mathrm{Br} J$ Sports Med 2006;40:387-91.

25 Spencer M, Bishop D, Dawson B, et al. Physiological and metabolic responses of repeated-sprint activities: specific to field-based team sports. Sports Med 2005:35:1025-44.

26 Reid M, Quinn A, Crespo M. Strength and conditioning for tennis. International Tennis Federation, 2003.

27 Bourdon P. Blood lactate thresholds: concepts and applications. In: Gore CJ, Tanner RK. eds Physiological tests for elite athletes. 2nd edn. Champaign Human Kinetics, 2013:77-102

28 Gore CJ, Tanner RK, Fuller KL, et al. Determination of maximal oxygen consumption (VO2max). In: Gore CJ, Tanner RK. eds Physiological tests for elite athletes. 2nd edn. Champaign Human Kinetics, 2013:103-22.

29 Ferrauti A, Weber K, Wright P. Endurance: basic, semi-specific and specific. Strength and conditioning for tennis. London: ITF, 2003:93-111.

30 Maksud MG, Coutts KD. Application of the Cooper twelve-minute run-walk test to young males. Res Q 1971;42:54-9.

31 Leger L, Boucher R. An indirect continuous running multistage field test: the Universite de Montreal track test. Can J App/ Sport Sci 1980;5:77-84.

32 Chtara M, Chamari K, Chaouachi M, et al. Effects of intra-session concurrent endurance and strength training sequence on aerobic performance and capacity. Br J Sports Med 2005;39:555-60.

33 Léger LA, Lambert J. A maximal multistage 20-m shuttle run test to predict V02 max. Eur J Appl Physiol Occup Physiol 1982;49:1-12

34 Leger LA, Mercier D, Gadoury C, et al. The multistage 20 metre shuttle run test for aerobic fitness. J Sports Sci 1988;6:93-101.

35 Bangsbo J, laia FM, Krustrup P. The Yo-Yo intermittent recovery test: a useful too for evaluation of physical performance in intermittent sports. Sports Med 2008:38:37-51.

36 Buchheit M. The 30-15 intermittent fitness test: accuracy for individualizing interval training of young intermittent sport players. J Strength Cond Res 2008;22:365-74.

37 Reid M, Sibte N, Clark S, et al. Tennis players. In: Gore CJ, Tanner RK. eds Physiological tests for elite athletes 2nd edn. Champaign Human Kinetics, 2013:449-61.

38 Buchheit M, Rabbani A. 30-15 Intermittent Fitness Test vs. Yo-Yo Intermittent Recovery Test Level 1: relationship and sensitivity to training. Int J Sports Physiol Perform 2013 [Epub ahead of print].

39 Dellal A, Varliette C, Owen A, et al. Small-sided games versus interval training in amateur soccer players: effects on the aerobic capacity and the ability to perform intermittent exercises with changes of direction. J Strength Cond Res 2012:26:2712-20

40 Weber K. Der Tennisport aus intemistich sportmedizinisher sichl. Schriften der Deutschen Sporthoschule Koln 1987;18:19-21.

41 Vergauwen L, Spaepen AJ, Lefevre J, et al. Evaluation of stroke performance in tennis. Med Sci Sports Exerc 1998;30:1281-8.

42 Smekal G, Pokan R, von Duvillard SP, et al. Comparison of laboratory and 'on-court' endurance testing in tennis. Int J Sports Med 2000;21: 242-9.

43 Davey PR, Thorpe RD, Williams C. Fatigue decreases skilled tennis performance. J Sports Sci 2002;20:311-18.

44 Baiget $\mathrm{E}$, Fernández-Fernández J, Iglesias $\mathrm{X}$, et al. On-court endurance and performance testing in competitive male tennis players. J Strength Cond Res 2014:28:256-64.

45 Weber K, Hollmann W. Neue Methoden zur Diagnostik und Trainingssteuerung der tennisspezifischen Ausdauerleistungsfähigkeit. In: Gabler HaZ B. ed Talentsuche und Talentförderung im Tennis. Ahrensberg: Czwalina, 1984:186-209.

46 Urso R, Okuno N, Gomes R, et al. Validity and reliability evidences of the Hit \& Turn Tennis Test. Sci Sports 2013.

47 Fernandez-Fernandez J, Kinner V, Ferrauti A. The physiological demands of hitting and running in tennis on different surfaces. J Strength Cond Res 2010:24:3255-64. 
48 Minahan. MAOCL. Anaerobic capacity. In: Gore RKTCJ. ed Physiological tests for elite athletes. Champaign: Human Kinetics, 2013:59-76.

49 Barker AR, Armstrong N. Insights into developmental muscle metabolism through the use of 31P-magnetic resonance spectroscopy: a review. Pediatr Exerc Sci 2010;22:350.

50 Noordhof DA, de Koning JJ, Foster C. The maximal accumulated oxygen deficit method: a valid and reliable measure of anaerobic capacity? Sports Med 2010;40:285-302.

51 Inbar 0, Bar-Or 0, Skinner JS. The Wingate anaerobic test. IL: Human Kinetics Champaign, 1996.

52 Kovacs MS, Pritchett R, Wickwire PJ, et al. Physical performance changes after unsupervised training during the autumn/spring semester break in competitive tennis players. Br J Sports Med 2007;41:705-10.

53 Ziemann E, Sledziewska E, Grzywacz T, et al. Body composition and physical capacity of elite adolescent female tennis players. Georgian Med News 2011(196-197):19.

54 Lakomy HKA. The use of a non-motorised treadmill for analysing sprint performance. Ergonomics 1987;30:627-37.

55 Tong $\mathrm{R}$, Bell W, Ball G, et al. Reliability of power output measurements during repeated treadmill sprinting in rugby players. J Sports Sci 2001;19: 289-97.

56 Carling C, Le Gall F, Dupont G. Analysis of repeated high-intensity running performance in professional soccer. J Sports Sci 2012:30:325-36.

57 Ratel S, Williams C, Oliver J, et al. Effects of age and recovery duration on performance during multiple treadmill sprints. Int J Sports Med 2006;27:1-8.

58 Spriet LL, Howlett RA, Heigenhauser GJF. An enzymatic approach to lactate production in human skeletal muscle during exercise. Med Sci Sports Exerc 2000;32:756-63

59 Bleicher A, Mader A, Mester J. Zur Interpretation von Laktatleistungskurvenexperimentelle Ergebnisse mit computergestützten Nachberechnungen. Spektrum der Sportwissenschaften 1998;10:92-104.

60 Dawson B. Repeated-sprint ability: where are we? Int I Sports Physiol Perform 2012;7:285-9.

61 Girard 0, Mendez-Villanueva A, Bishop D. Repeated-sprint ability-part I: factors contributing to fatigue. Sports Med 2011;41:673-94.

62 Bishop D, Girard O, Mendez-Villanueva A. Repeated-sprint ability-part II: recommendations for training. Sports Med 2011;41:741-56.

63 Fernandez-Fernandez J, Zimek R, Wiewelhove T, et al. High-intensity interval training vs. repeated-sprint training in tennis. J Strength Cond Res 2012;26:53-62.

64 Spencer M, Lawrence S, Rechichi C, et al. Time-motion analysis of elite field hockey, with special reference to repeated-sprint activity. J Sports Sci 2004;22: 843-50.

65 Buchheit M. Repeated-sprint performance in team sport players: associations with measures of aerobic fitness, metabolic control and locomotor function. Int J Sports Med 2012;33:230-9.

66 Kovacs MS, Ellenbecker TS. A performance evaluation of the tennis serve: implications for strength, speed, power, and flexibility training. Strength Cond J 2011;33:22.

67 Reid M, Schneiker K. Strength and conditioning in tennis: current research and practice. J Sci Med Sport 2008;11:248-56.

68 Cronin JB, Henderson ME. Maximal strength and power assessment in novice weight trainers. J Strength Cond Res 2004;18:48-52.

69 Cronin JB, Hansen KT. Strength and power predictors of sports speed. J Strength Cond Res 2005; 19:349-57.

70 Cormie P, McGuigan MR, Newton RU. Developing maximal neuromuscular power. Sports Med 2011;41:17-38.

71 Kelln BM, McKeon PO, Gontkof LM, et al. Hand-held dynamometry: reliability of lower extremity muscle testing in healthy, physically active, young adults. J Sport Rehabil 2008;17:160.

72 Hayes K, Walton JR, Szomor ZL, et al. Reliability of 3 methods for assessing shoulder strength. J Shoulder Elbow Surg 2002;11:33-9.

73 McGuigan MR, Winchester JB. The relationship between isometric and dynamic strength in college football players. J Sports Sci Med 2008;7:101-05.

74 Murphy AJ, Wilson GJ. The ability of tests of muscular function to reflect training-induced changes in performance. J Sports Sci 1997;15:191-200.

75 Ducher G, Courteix D, Meme S, et al. Bone geometry in response to long-term tennis playing and its relationship with muscle volume: a quantitative magnetic resonance imaging study in tennis players. Bone 2005;37:457-66.

76 Juzwiak CR, Amancio OMS, Vitalle MS, et al. Body composition and nutritional profile of male adolescent tennis players. J Sports Sci 2008;26:1209-17.

77 Savva C, Karagiannis C, Rushton A. Test-retest reliability of grip strength measurement in full elbow extension to evaluate maximum grip strength. $J$ Hand Surg 2013;38:183-6.

78 Wisløff U, Castagna C, Helgerud J, et al. Strong correlation of maximal squat strength with sprint performance and vertical jump height in elite soccer players. Br J Sports Med 2004;38:285-8.
79 Brown L, Weir J. Accurate assessment of muscular strength and power, ASEP procedures recommendation. J Exerc Physiol 2001;4:1-21.

80 Baker $D$, Nance $S$. The relation between running speed and measures of strength and power in professional rugby league players. I Strength Cond Res 1999:13:230-5.

81 Reynolds JM, Gordon TJ, Robergs RA. Prediction of one repetition maximum strength from multiple repetition maximum testing and anthropometry. I Strength Cond Res 2006;20:584-92.

82 Ellenbecker TS, Davies GJ. The application of isokinetics in testing and rehabilitation of the shoulder complex. J Athl Train 2000:35:338.

83 Davies GJ. A compendium of isokinetics in clinical usage and rehabilitation techniques. S\&S Publishers, 1992.

84 Cohen DB, Mont MA, Campbell KR, et al. Upper extremity physical factors affecting tennis serve velocity. Am J Sports Med 1994:22:746-50.

85 Ellenbecker TS, Roetert EP. Testing isokinetic muscular fatigue of shoulder internal and external rotation in elite junior tennis players. J Orthop Sports Phys Ther 1999;29:275-81.

86 Treiber FA, Lott J, Duncan J, et al. Effects of Theraband and lightweight dumbbell training on shoulder rotation torque and serve performance in college tennis players. Am J Sports Med 1998;26:510-15.

87 Mont MA, Cohen DB, Campbell KR, et al. Isokinetic concentric versus eccentric training of shoulder rotators with functional evaluation of performance enhancement in elite tennis players. Am J Sports Med 1994:22:513-17.

88 Perry AC, Wang $X$, Feldman BB, et al. Can laboratory-based tennis profiles predict field tests of tennis performance? J Strength Cond Res 2004; 18:136-43.

89 Ellenbecker TS, Roetert EP. An isokinetic profile of trunk rotation strength in elite tennis players. Med Sci Sports Exerc 2004;36:1959-63.

90 Roetert E, McCormick T, Brown S, et al. Relationship between isokinetic and functional trunk strength in elite junior tennis players. Isokinet Exerc Sci 1996;6:15-20.

91 Signorile J, Sandler D, Smith W, et al. Correlation analyses and regression modeling between isokinetic testing and on-court performance in competitive adolescent tennis players. J Strength Cond Res 2005:19:519-26.

92 Cronin J, Sleivert G. Challenges in understanding the influence of maximal power training on improving athletic performance. Sports Med 2005;35: 213-34

93 Girard O, Micallef JP, Millet GP. Lower-limb activity during the power serve in tennis: effects of performance level. Med Sci Sports Exerc 2005;37:1021-9.

94 Elliott B. Biomechanics and tennis. Br J Sports Med 2006;40:392-6.

95 Ellenbecker TS, Roetert EP. An isokinetic profile of trunk rotation strength in elite tennis players. Med Sci Sports Exerc 2004;36:1959-63.

96 Ikeda Y, Kijima K, Kawabata K, et al. Relationship between side medicine-ball throw performance and physical ability for male and female athletes. Eur J App Physiol 2007:99:47-55

97 T Cable KG. ed Impact of physical performance on tennis ranking in juniors-results from nationwide German tennis test (Abstract). 16th Annual Congress of the European College of Sports Science. Liverpool: ECSS, 2011.

98 Hornery DJ, Farrow D, Mujika I, et al. Caffeine, carbohydrate, and cooling use during prolonged simulated tennis. Int J Sports Physiol Perform 2007;2:423.

99 Vergauwen L, Madou B, Behets D. Authentic evaluation of forehand groundstrokes in young low- to intermediate-level tennis players. Med Sci Sports Exerc 2004;36:2099-106.

100 Fernandez-Fernandez J, Ellenbecker T, Sanz-Rivas D, et al. Effects of a 6-Week Junior Tennis Conditioning Program on Service Velocity. J Sports Sci Med 2013;12:232-9.

101 Ferrauti A, Bastiaens K. Short-term effects of light and heavy load interventions on service velocity and precision in elite young tennis players. $\mathrm{Br} J$ Sports Med 2007:41:750-3.

102 Sheppard JM, Young WB. Agility literature review: classifications, training and testing. J Sports Sci 2006;24:919-32.

103 Little T, Williams AG. Specificity of acceleration, maximum speed, and agility in professional soccer players. J Strength Cond Res 2005;19:76-8.

104 Brughelli M, Cronin J, Levin G, et al. Understanding change of direction ability in sport: a review of resistance training studies. Sports Med 2008;38:1045-63.

105 Stewart PF, Turner AN, Miller SC. Reliability, factorial validity, and interrelationships of five commonly used change of direction speed tests. Scand J Med Sci Sports 2012. [Epub ahead of print].

106 Beekhuizen KS, Davis MD, Kolber MJ, et al. Test-retest reliability and minimal detectable change of the hexagon agility test. J Strength Cond Res 2009:23:2167-71.

107 Gamble P. Strength and conditioning for team sports: sport-specific physical preparation for high performance. Routledge, 2013.

108 Cooke K, Quinn A, Sibte N. Testing speed and agility in elite tennis players. Strength Cond J 2011;33:69-72.

109 Pluim BM, Staal JB, Windler GE, et al. Tennis injuries: occurrence, aetiology, and prevention. Br J Sports Med 2006;40:415-23. 


\section{Review}

110 Kibler WB, Uhl TL, Maddux JW, et al. Qualitative clinical evaluation of scapular dysfunction: a reliability study. I Shoulder Elbow Surg 2002;11:550-6.

111 Ellenbecker TS. Physical examination of the shoulder. Saunders, 2004

112 Peeler J, Anderson J. Reliability of the Thomas test for assessing range of motion about the hip. Phys Ther Sport 2007:8:14-21.

113 Magee DJ. Orthopaedic physical assessment. Elsevier Health Sciences, 2008.

114 Cook G, Burton L, Hoogenboom B. Pre-participation screening: the use of fundamental movements as an assessment of function-part 1. N Am J Sports Phys Ther 2006;1:62.

115 Minick KI, Kiesel KB, Burton L, et al. Interrater reliability of the functional movement screen. J Strength Cond Res 2010;24:479-86.
116 Gribble PA, Brigle J, Pietrosimone BG, et al. Intrarater reliability of the functional movement Screen. J Strength Cond Res 2013;27:978-81.

117 Elias JE. The inter-rater reliability of the Functional Movement Screen within an athletic population using Untrained Raters. J Strength Cond Res 2013. [Epub ahead of print].

118 Smith CA, Chimera NJ, Wright NJ, et al. Interrater and intrarater reliability of the functional movement screen. J Strength Cond Res 2013;27:982-7.

119 Schneiders AG, Davidsson $\AA$, Hörman E, et al. Functional Movement Screen normative values in a young, active population. Int I Sports Phys Ther 2011; $6: 75$. 